\title{
Sheep breed and shearing influences attraction and blood-feeding behaviour of Culicoides (Diptera: Ceratopogonidae) on a UK farm
}

Andrew Hope ${ }^{1 *}$, Simon Gubbins ${ }^{1}$, Christopher Sanders ${ }^{1}$, James Barber ${ }^{1}$, Francesca Stubbins ${ }^{1}$, Matthew Baylis ${ }^{2,3}$ and Simon Carpenter ${ }^{1}$

\begin{abstract}
Background: Culicoides biting midges (Diptera: Ceratopogonidae) are responsible for the biological transmission of arboviruses of international importance between ruminant livestock. These arboviruses include bluetongue virus (BTV) and Schmallenberg virus (SBV), which have emerged in unprecedented outbreaks in northern Europe. The impact of breed and shearing of sheep on Culicoides: host contact rates has not been investigated in detail and has the potential to influence arbovirus transmission and control measures employed to limit spread.

Methods: Attraction of Culicoides to Hartline and Hartline/Suffolk cross-breed sheep was compared using 224 drop trap collections over 22 nights and 181 catches from sheared or unsheared Hartline/Suffolk ewes were made over 17 nights to compare Culicoides activity and rates of blood engorgement.

Results: A total of 31,314 Culicoides was collected in the two trials and females of the subgenus Avaritia represented over $96.9 \%$ of individuals collected. Attraction to breed was dependent upon species of Culicoides and physiological status, with a significantly greater number of individuals collected on the cross-breed sheep. Shearing of sheep did not significantly increase or decrease the number of Culicoides attracted but increased the rate of successful engorgement.

Conclusions: Both breed and shearing were shown to influence Culicoides biting rate on sheep. These data are useful in a direct context in understanding the likely impact of control measures against arboviruses including BTV and SBV and additionally in providing data from field-based studies to enable modelling exercises of arbovirus transmission and spread.
\end{abstract}

Keywords: Bluetongue virus, Schmallenberg virus, Animal husbandry, Vector, Arbovirus, Host location

\section{Background}

Culicoides biting midges (Diptera: Ceratopogonidae) are biological vectors of internationally important arboviruses $[1,2]$. Bluetongue virus (BTV) and Schmallenberg virus (SBV) epidemics have inflicted major economic impact on farms across Europe, not only in causing direct clinical disease (most commonly in sheep), but also in leading to the imposition of animal movement restrictions to limit disease spread $[3,4]$. Vaccination of susceptible

\footnotetext{
* Correspondence: andrew.hope@lstmed.ac.uk

'The Pirbright Institute, Pirbright, Surrey, UK

Full list of author information is available at the end of the article
}

livestock against these arboviruses is a highly effective tool in combating incursions in Europe and has been used several times successfully to eradicate BTV from countries $[5,6]$. Use of vaccines does, however, require a substantial period of time to implement due to assessment of outbreak impact (which determines commercial production), development, testing and registration. Prior to the use of vaccines, the only control measures available to limit spread and impact of Culicoides-borne arboviruses are those aimed at reducing Culicoides, host contact [7-9] and ruminant movement restrictions.

(c) The Author(s). 2018 Open Access This article is distributed under the terms of the Creative Commons Attribution 4.0 International License (http://creativecommons.org/licenses/by/4.0/), which permits unrestricted use, distribution, and 
It has long been suggested that sheep breeds vary in their susceptibility to clinical diseases caused by Culicoides-borne arboviruses, although evidence from standardised studies involving needle inoculation is equivocal $[10,11]$. Studies of other haematophagous dipteran groups have also illustrated that both inter- and intraspecific variation in biting pressure occurs within host species $[12,13]$. This variation in response reflects a highly complex and often interrelated combination of visual, thermal and semiochemical cues that are used in host-location $[14,15]$. Differential responses to hosts have been investigated between humans for Culicoides impunctatus Goetghebuer, a nuisance biting species in the UK [16], and for Culicoides sonorensis Wirth \& Jones feeding on cattle in the USA [17]. Additionally, differences between livestock species have been investigated in France [18] and the Netherlands [19]. To date, however, no systematic assessment of attraction of Culicoides to different breeds of livestock have been made.

A wide range of examples of inter-breed differences in ectoparasite numbers and impact on ruminant livestock have been documented for arthropod groups including ticks [20, 21], flies [22-24] and mites [25]. A large proportion of studies have been conducted on the horn fly, Haematobia irritans L. which is relatively straightforward to accurately record on cattle hosts by observation. Variation in ectoparasite load can occur due to a wide, and usually undefined, range of physical and behavioural differences between breeds, the degree of specialisation of the ectoparasite concerned and differences in husbandry methods used in production. To date, differences in attraction to sheep breeds have not been explored in Culicoides, although evidence of preferential feeding sites for species have been documented in Europe on livestock and horses [26-28].

A combination of shearing of sheep in early summer to allow wool regrowth before the BTV vector season and treatment with insect repellents has been anecdotally suggested to lead to reductions in the incidence of clinical signs of BTV in South Africa [29]. This is hypothesised to be a result of the fleece acting as a more substantial mechanical barrier to blood-feeding by Culicoides at times of high biting pressure. Studies of host preference have also demonstrated that the biting pressure of Culicoides on sheep tends to be significantly lower than that found on larger hosts such as cattle and horses, hence techniques that mitigate against transmission may have a greater impact for this species where the probability of transmission is already marginal $[19,30]$. The impact of fleece length has been investigated in the field for fly strike (myiasis) inflicted by blowflies (family Calliphoridae), where clipping of the fleece, tail docking and mulesing have traditionally been used to reduce impact $[31,32]$. To date, however, we are not aware of any studies that have examined the influence of fleece length on blood-feeding by adult biting flies on sheep.

The aim of this study was therefore to investigate the influence of breed and shearing on host: vector relationships in the field using a modified design of drop traps developed in previous investigations [33]. Data from these areas will provide an initial assessment of the potential impact of these techniques on mitigating against BTV transmission and also inform modelling approaches through the provision of vector: host ratios. Methods and results produced during this study have been previously published in the form of a $\mathrm{PhD}$ thesis [34].

\section{Methods}

\section{Study site}

All studies were carried out at a mixed cattle and sheep farm in Bradfield, Berkshire, UK $\left(51^{\circ} 27^{\prime} 09.40^{\prime \prime} \mathrm{N}, 1^{\circ}\right.$ $\left.09^{\prime} 41.82 " \mathrm{~W}\right)$. The specific field location used fell into a $1 \mathrm{~km}^{2}$ cell with dominant habitat type of "broadleaved, mixed and Yew woodland" and adjacent cells dominated by "broadleaved, mixed and Yew woodland", "improved grassland" and "arable and horticulture". Meteorological data was collected using an automatic weather station (CR800 data logger, Campbell Scientific, UK) recording average conditions every 15 min throughout sampling periods. Data collected were: air temperature $\left({ }^{\circ} \mathrm{C}\right)$; relative humidity (\%); solar intensity $\left(\mathrm{Wm}^{-2}\right)$; wind speed $\left(\mathrm{ms}^{-1}\right)$ and wind direction $\left(^{\circ}\right)$. For data analysis, wind direction was transformed using the ArcTangent2 function in Microsoft Excel as it is a circular variable and therefore wind direction at $0^{\circ}$ and $360^{\circ}$ represent the same direction.

\section{Culicoides trapping procedures}

A drop trap was constructed with a rectangular metal base frame measuring $3 \mathrm{~m}$ length by $2.4 \mathrm{~m}$ width and three arches were attached to the base frame giving a maximum height of $2.1 \mathrm{~m}$ (Fig. 1). The drop trap was further supported by a wooden frame on the outside of the structure. White netting with mesh size of less than $0.25 \mathrm{~mm}^{2}$ was attached to the metal frame and could be raised and lowered as required. In order to retain sheep inside the drop trap a rectangular enclosure was created using open sided fencing panels. Prior to Culicoides collection, sheep were herded into a corral positioned next to the drop trap where they could be held throughout the sampling period. For each collection sheep were herded into the drop trap with the netting raised. Investigators moved to a distance of at least $100 \mathrm{~m}$ from the trap for an exposure period of ten minutes. The investigators then returned, the netting was dropped and all Culicoides retained inside the net were collected using a manual aspirator during a $10 \mathrm{~min}$ period. Culicoides were transferred to pillboxes (Watkins \& Doncaster, Leominster, UK), which were then placed in sealed plastic containers 

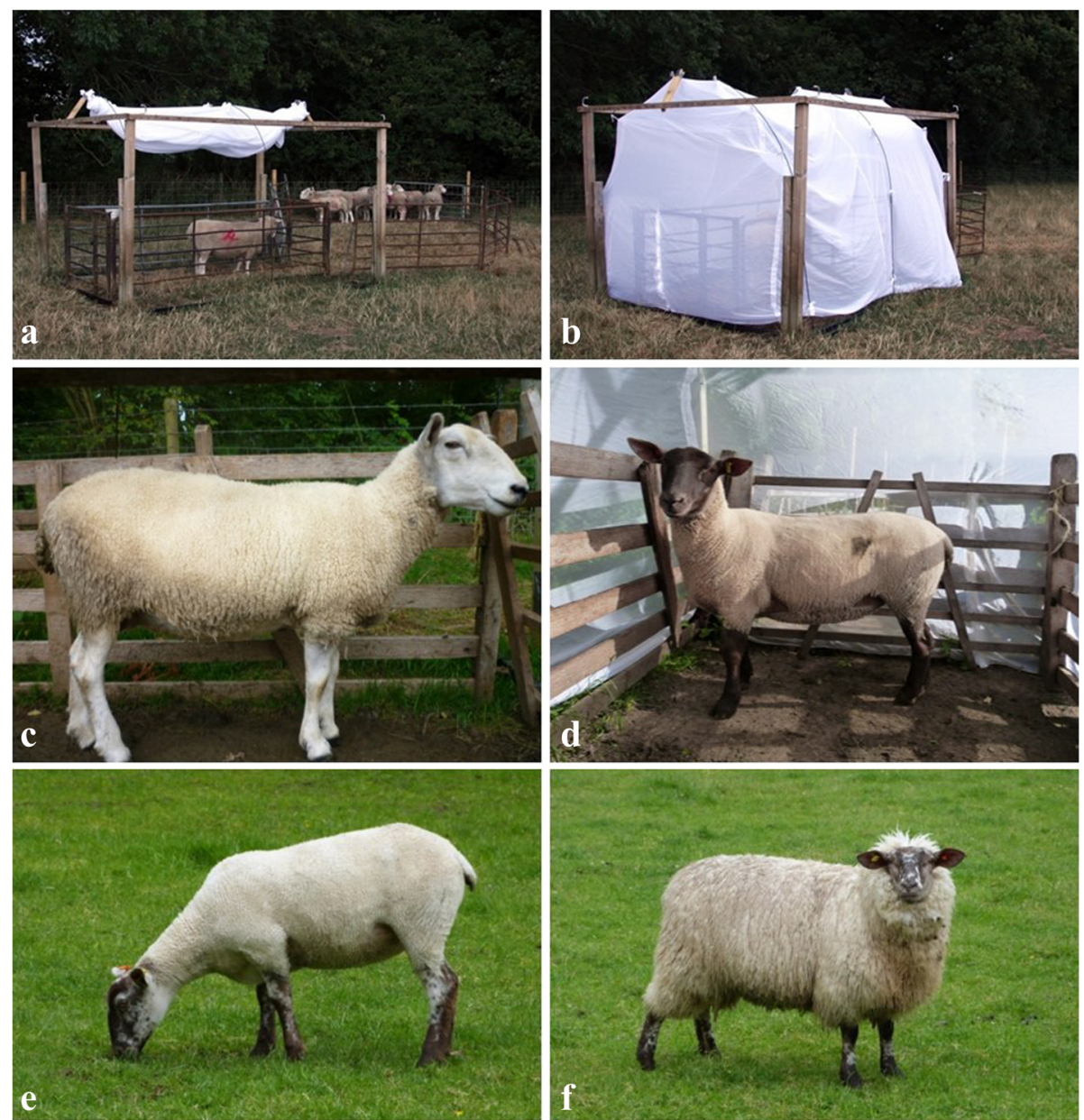

Fig. 1 Trapping techniques and hosts used during trials. Panels $\mathbf{a}$ and $\mathbf{b}$ show the drop trap design pre- and post-deployment and the connecting corral containing sheep not used in experimentation. Panels $\mathbf{c}$ and $\mathbf{d}$ show the Hartline and Hartline/Suffolk cross sheep used in the breed comparison study (Trial 1). Panels e and $\mathbf{f}$ show the sheared and unsheared Hartline/Suffolk sheep (Trial 2)

with chloroform to kill samples before transfer to $70 \%$ ethanol. For each trial a UV light-suction trap was operated as a positive control (Model 912, John W Hock Inc., USA); the trap was positioned at a distance of at least 50 $\mathrm{m}$ from the drop trap and two light trap positions were used with the trap switching position each night.

\section{Trial one: inter-breed variation in Culicoides attraction}

The trial was conducted from $27 / 6 / 2011$ to $28 / 07 / 2011$ [34]. Two breeds of sheep were used: Hartline (a breed originating in the 1970s from a four-way cross of Welsh halfbred/Finn Colbred/Friesland and Texel) and Hartline/ Suffolk cross (Fig. 1). Ten females of each breed weighing between $70-80 \mathrm{~kg}$ were used and each had a lamb, although collections were only carried out on adults. For each drop trap collection, three individuals of the same breed were used with collections alternating between the two breeds. Collections were carried out from $3 \mathrm{~h}$ before sunset to $1 \mathrm{~h}$ after; the UV light-suction trap was operated continuously for the $4 \mathrm{~h}$ trapping period and hence was not included in the analysis.

\section{Trial two: collection of Culicoides from sheared and unsheared sheep}

This trial was conducted from 16/05/2012 to $02 / 06 / 2012$ in the same field as trial one but the location of the drop trap was moved [34]. Twelve Hartline/Suffolk ewes weighing between $70-80 \mathrm{~kg}$ were used in two groups, six were sheared in the week prior to the start of the trial and six remained unsheared. Collections were made using groups of three sheep and conducted from $3 \mathrm{~h}$ before sunset to 1 hour after sunset, the UV light-suction trap was examined after each drop trap collection.

\section{Morphological and molecular identification of Culicoides}

All collections were initially identified morphologically as Culicoides by wing pattern using a stereo-microscope [35, 36]. Female Culicoides were identified by observation 
of the abdomen as unpigmented; pigmented; gravid or blood-fed [37, 38]. For Culicoides of the subgenus Avaritia, identification of females was carried out using morphology for Culicoides chiopterus Meigen (where wing markings are pale and body size is reduced). For Culicoides obsoletus Meigen, Culicoides scoticus Downes \& Kettle and Culicoides dewulfi Goetghebuer, a multiplex polymerase chain reaction (PCR) assay was used for differentiation [39].

To extract DNA, Culicoides were removed from 70\% ethanol storage and allowed to dry for $10 \mathrm{~min}$ on paper tissue before being placed individually into $2 \mathrm{ml}$ microcollection tubes (Qiagen, Manchester, UK). Each tube contained $10 \mu \mathrm{l}$ of $2 \%$ proteinase-k (Bioline, London, UK) in solution with tris calcium acetate and $200 \mu \mathrm{l}$ of $5 \%$ chelex (Bio-Rad, Watford, UK). Samples were homogenised in two cycles of two minutes at $25 \mathrm{~Hz}$ in a Tissuelyser (Qiagen), then incubated overnight at $37{ }^{\circ} \mathrm{C} .4 \mu \mathrm{l}$ of each sample was removed and added to a 96 well PCR plate (Abgene, Ashford, UK). These samples were subjected to an 8 min cycle at $99^{\circ} \mathrm{C}$ to deactivate the proteinase $\mathrm{K}$.

PCR master mix for each PCR plate consisted: $25 \mu \mathrm{l}$ of $10 \mu \mathrm{M}$ forward primer specific to each species (C. obsoletus: 5'-TGC AGG AGC TTC TGT AGA TTT G-3'; $C$. scoticus: 5'-ACC GGC ATA ACT TTT GAT CG-3'; $C$. dewulfi: 5'-ATA CTA GGA GCG CCC GAC AT-3') [40]; $25 \mu \mathrm{l}$ DNAse free water; $100 \mu \mathrm{l}$ of $10 \mu \mathrm{M}$ universal reverse primer (5'-CAG GTA AAA TTA AAA TAT AAA CTT CTG G-3') [41]; $7 \mu \mathrm{l} \mathrm{MgCl}$ solution; $400 \mu \mathrm{l}$ Biomix Red solution (Bioline, UK), $6 \mu \mathrm{l}$ of master mix was added to each $4 \mu$ sample of extracted DNA. In addition to the test samples, each plate also contained 3 positive controls, using DNA extracted from males of each species using spin column methods with the protocol supplied by the manufacturer (Qiagen), and 3 negative controls consisting of $4 \mu \mathrm{l}$ of DNAse free water. Samples were subjected to PCR with the following profile: initial denaturing step at $94{ }^{\circ} \mathrm{C}$ for $4 \mathrm{~min} ; 32$ cycles at $94{ }^{\circ} \mathrm{C}$ for $30 \mathrm{~s}, 60^{\circ} \mathrm{C}$ for $30 \mathrm{~s}$, $72{ }^{\circ} \mathrm{C}$ for $1 \mathrm{~min}$; followed by a final extension step at $72{ }^{\circ} \mathrm{C}$ for $5 \mathrm{~min}$. PCR products were examined by electrophoresis using 2\% agarose e-gels (Invitrogen, Glasgow, UK) and identified as species according to band position against positive controls.

Due to the size of the data sets generated in the trials it was not practical to identify all individuals by molecular analysis and a sub-sample method was used. For each trial, five nights of sampling were randomly selected and the entire collections from those nights were subjected to molecular analysis. The proportions of species and physiological states generated by the sub-samples in each trial were then applied to the remaining samples from each trial to infer species and physiological state for the other samples from that trial. Any samples that failed to amplify during molecular analysis were excluded from the final estimates.

\section{Data analysis}

Data were analysed using generalised linear models (GLM) assuming a negative binomial distribution and a log link function in $\mathrm{R}$ version 2.15.2 [42]. Models were generated for total numbers of females collected per species and separately for physiological state; all analyses included meteorological variables [34]. Initially, each model included air temperature, relative humidity, solar radiation, wind speed and transformed wind direction. Trap type was included along with a linear and a quadratic temporal trend (number of days since the trial began). Final models were generated using stepwise deletion of non-significant $(P>0.05)$ variables with a final model constructed where all variables are significant $(P<0.05)$ (assuming a linear relationship between log catch size and each meteorological variable). The effects of individual factors in the final model were examined using Tukey's honest significant differences post-hoc test to identify significant differences $(P<0.05)$ between factor levels. Because of the large number of comparisons, a second analysis was carried out in which a Bonferroni correction was applied to set the significance level required for inclusion of a factor in the final model (i.e. the $P$-value, 0.05 , divided by the number of comparisons). In this case, significance in trial one was set to $P<0.0033$ and in trial two it was set to $P<0.0036$. Applying the Bonferroni correction did not result in differences in the final models and, hence, is not included in the results.

\section{Results}

Trial one: inter-breed variation in Culicoides attraction

A total of 224 collections were made from the sheep using the drop trap, 112 from each breed and 22 from the UV light-suction trap (Table 1, Fig. 2). Of 16,151 Culicoides collected, 8381 were taken from the cross-breed, 6483 from the pure-breed and 1287 from the light trap. The average Culicoides collection for the 10 min exposure period was 74.8 (SEM \pm 7.79$)$ for the cross-bred sheep and 57.9 (SEM \pm 6.87 ) for the pure-breed, equating to 24.9 and 19.3 for individual sheep. The largest single collection on the cross-breed was 495 Culicoides and for the pure-breed 472, equating to a mean rate on individuals of 165 and 157.3/10 min exposure, respectively. In the light trap the greatest single collection was 498 , but this was recorded for the entire four-hour trapping period. Over the course of the trial there were only two collections on sheep where zero Culicoides were collected, one for each breed; there were no zero collections made with the light-suction trap.

Of the Culicoides collected, $97.3 \%$ were females of the subgenus Avaritia (Table 1). Other Culicoides species constituted 2.7\% of catches: Culicoides achrayi Kettle \& Lawson (1.3\%), Culicoides punctatus Meigen (0.5\%) and the remaining $0.9 \%$ comprised rarer species including 
Table 1 Total numbers of Culicoides spp. collected using drop trap sampling on two breeds of sheep and from light-suction trap controls (Trial 1)

\begin{tabular}{|c|c|c|c|c|c|c|}
\hline \multirow[t]{2}{*}{ Trap } & \multicolumn{6}{|c|}{ Genus/Subgenus/Species } \\
\hline & $\begin{array}{l}\text { Total Culicoides } \\
\text { spp. }\end{array}$ & $\begin{array}{l}\text { Subgenus Avaritia } \\
\text { females }\end{array}$ & $\begin{array}{l}\text { C. obsoletus } \\
\text { males }\end{array}$ & $\begin{array}{l}\text { C. scoticus } \\
\text { males }\end{array}$ & $\begin{array}{l}\text { C. dewulfi } \\
\text { males }\end{array}$ & $\begin{array}{l}\text { C. chiopterus } \\
\text { males }\end{array}$ \\
\hline Cross-breed $(n=112)$ & 8381 & 8247 & 20 & 7 & 1 & 1 \\
\hline Pure-breed $(n=112)$ & 6483 & 6364 & 34 & 10 & 1 & 1 \\
\hline Light-suction trap $(n=22)$ & 1287 & 1103 & 7 & 19 & 4 & 1 \\
\hline Total & 16,151 & 15,714 & 61 & 36 & 6 & 3 \\
\hline
\end{tabular}

Culicoides pulicaris L., Culicoides brunnicans Edwards and C. impunctatus. A total of 2572 individuals identified morphologically as $C$. obsoletus, $C$. scoticus or $C$. dewulfi were subjected to molecular identification through multiplex PCR. Of these, 2458 (95.6\%) were successfully amplified and the remaining 114 (4.4\%) failed to amplify as a result of poor DNA extraction. Of the successfully amplified samples, 1268 (51.6\%) were C. obsoletus, 936 (38.1\%) were C. scoticus and $254(10.3 \%)$ were C. dewulfi. Total numbers for these species and physiological states were calculated based on these sub-sample proportions (Table 2).

Statistical analyses of collections on the two breeds of sheep were restricted to investigating differences between the breeds without the direct inclusion of data from the light-suction trap and therefore Tukey's testing was not necessary as differences between collections between the two breeds are shown in the models. Four models per species were generated to describe the collections of $C$. obsoletus, $C$. scoticus and $C$. dewulfi females from the two breeds of sheep: total females (includes all physiological states); unpigmented females, pigmented females and blood-fed females (Additional file 1: Tables S1-S3). Due to low numbers of unpigmented $C$. chiopterus females collected only three models were generated for this species: total C. chiopterus females; pigmented females; and blood-fed females.

Summary statistics for models produced are provided in Additional file 1. Across all four models generated to describe collections of $C$. obsoletus and the three models for $C$. chiopterus, the analyses revealed that catches on the pure- and cross-breeds did not differ significantly $(P>0.05)$ (Additional file 1: Tables S1 and S4). Analysis of C. scoticus data revealed that collections differed significantly between the two breeds when considering total

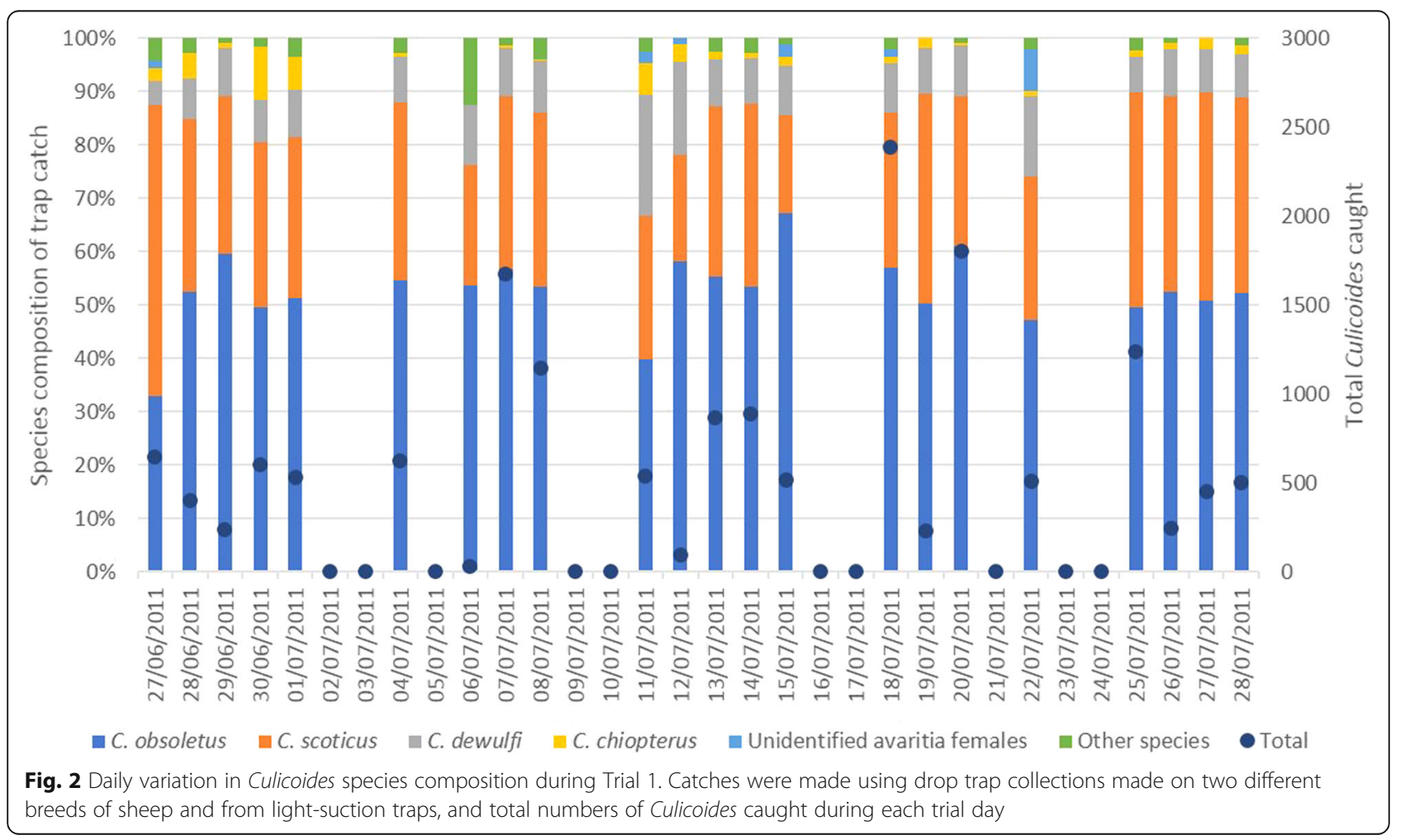


Table 2 Abundance of Culicoides spp. of the subgenus Avaritia and physiological states calculated from sub-samples of total collections during Trial One

\begin{tabular}{|c|c|c|c|c|c|}
\hline Species & Physiological status & Cross-breed & Pure-breed & Light-suction trap & Total \\
\hline \multirow[t]{6}{*}{ C. obsoletus } & Unpigmented & 1672 & 1612 & 322 & 3606 \\
\hline & Pigmented & 1714 & 1482 & 152 & 3348 \\
\hline & Blood-fed & 700 & 862 & 6 & 1568 \\
\hline & Gravid & 30 & 12 & 46 & 88 \\
\hline & Male & 20 & 34 & 7 & 61 \\
\hline & Total & 4136 & 4002 & 533 & 8671 \\
\hline \multirow[t]{6}{*}{ C. scoticus } & Unpigmented & 870 & 710 & 283 & 1863 \\
\hline & Pigmented & 377 & 407 & 137 & 921 \\
\hline & Blood-fed & 1778 & 570 & 5 & 2353 \\
\hline & Gravid & 15 & 35 & 18 & 68 \\
\hline & Male & 7 & 10 & 19 & 36 \\
\hline & Total & 3047 & 1732 & 462 & 5241 \\
\hline \multirow[t]{6}{*}{ C. dewulfi } & Unpigmented & 368 & 217 & 22 & 607 \\
\hline & Pigmented & 446 & 205 & 17 & 668 \\
\hline & Blood-fed & 102 & 112 & 0 & 214 \\
\hline & Gravid & 5 & 0 & 9 & 14 \\
\hline & Male & 1 & 1 & 4 & 6 \\
\hline & Total & 922 & 535 & 52 & 1509 \\
\hline \multirow[t]{6}{*}{ C. chiopterus } & Unpigmented & 2 & 1 & 3 & 6 \\
\hline & Pigmented & 73 & 67 & 19 & 159 \\
\hline & Blood-fed & 63 & 52 & 0 & 115 \\
\hline & Gravid & 1 & 0 & 3 & 4 \\
\hline & Male & 1 & 1 & 1 & 3 \\
\hline & Total & 140 & 121 & 26 & 287 \\
\hline Total & & 8245 & 6390 & 1073 & 15,708 \\
\hline
\end{tabular}

females and blood-fed females $(P<0.001)$, but that no significant differences were found for unpigmented or pigmented individuals (Additional file 1: Table S2). Collections of $C$. dewulfi differed significantly between breeds $(P<0.001)$ with greater collections made on the cross-breed, with the exception of blood-fed females where no significant difference was found $(P>0.05)$ (Additional file 1: Table S3).

Temporal trends were significant across all four species $(P<0.05)$. Of the meteorological variables included, wind speed was highly significant in models of all species and physiological states $(P<0.001)$, with reduced catches associated with higher wind speeds. The relationships between trap catches and other meteorological variables were not significant $(P>0.05)$ for all species and physiological states, but where they were significant, the effect was consistent (Additional file 1: Tables S1-S4). Higher trap catches were associated with increased temperatures, with increased humidity and with decreased solar radiation.
Trial two: collection of Culicoides from sheared and unsheared sheep

A total of 362 collections were made during the trial, 181 in the UV light-suction trap, 90 on the unsheared sheep and 91 on the sheared sheep over 17 nights of sampling (Table 3, Fig. 3). The total number of Culicoides collected was 15,163 , including 14,613 (96.4\%) subgenus Avaritia females. Other species collected included C. brunnicans (1.92\%); C. achrayi (0.5\%) and $C$. pulicaris (0.4\%), while C. punctatus and C. impunctatus were collected in smaller numbers. The average Culicoides collection for the $10 \mathrm{~min}$ exposure period was $83.2(\mathrm{SEM} \pm 11.45)$ on the sheared sheep, 75.06 (SEM \pm $11.26)$ on the unsheared sheep and $4.62(\mathrm{SEM} \pm 3.29)$ for the UV light-suction trap. The largest single drop trap collection on the sheared sheep was 523, while the drop trap with the unsheared sheep collected a maximum of 505 individuals. The largest UV light-suction trap collection was 586 Culicoides. Assuming all these Culicoides fed successfully, this equated to 17.43 bites/ 
Table 3 Total numbers of Culicoides spp. collected on sheared and unsheared sheep and with a UV light-suction trap (Trial 2)

\begin{tabular}{|c|c|c|c|c|c|c|}
\hline \multirow[t]{2}{*}{ Trap type } & \multicolumn{6}{|c|}{ Genus/Subgenus/Species } \\
\hline & Total Culicoides & Subgenus Avaritia females & C. obsoletus males & C. scoticus males & C. dewulfi males & C. chiopterus males \\
\hline Sheared $(n=91)$ & 7571 & 7239 & 24 & 4 & 2 & 15 \\
\hline Unsheared $(n=90)$ & 6755 & 6565 & 26 & 3 & 8 & 13 \\
\hline Light-suction trap $(n=181)$ & 837 & 809 & 2 & 0 & 0 & 0 \\
\hline Total & 15,163 & 14,613 & 52 & 7 & 10 & 28 \\
\hline
\end{tabular}

min on unsheared individuals and 16.83 for sheared. Over the course of the trial there were only two collections on sheep where zero Culicoides were collected, one for each type of sheep, compared to 160 zero samples when using the light-suction trap.

Within the subgenus Avaritia, 1080 individuals were classified morphologically as female C. chiopterus. Of the remaining C. obsoletus, C. scoticus and C. dewulfi, 5050 individuals were subjected to molecular identification as a subsample. A total of 4915 individuals, representing 97.3\%, were successfully identified through PCR, the remaining 135 (2.67\%) failed to amplify. The results of the PCR revealed that the sub-sample comprised 1824 (37.1\%) C. obsoletus, 2903 (59.67\%) C. scoticus and 188 (3.36\%) C. dewulfi. For each treatment the proportion of physiological state per species calculated from the sub-sample was then applied to the remaining samples to impute total numbers and physiological states for each species (Table 4). For C. obsoletus and C. scoticus four models were generated to describe collections made on sheared and unsheared sheep: total females; unpigmented females; pigmented females; and blood-fed females (Additional file 1: Tables S5-S11). For C. dewulfi insufficient blood-fed individuals were collected for analysis and this was also the case for unpigmented females in C. chiopterus.

Summary statistics for models produced are provided in Additional file 1. No significant differences were observed in the total female models between sheared and unsheared sheep, unpigmented models or pigmented models for C. obsoletus, C. scoticus, C. dewulfi or C. chiopterus (Additional file 1: Tables S5-S11). In C. obsoletus, however, collections using the sheared sheep collected significantly higher numbers of blood-fed individuals than the unsheared $(P<0.001)$, though no such difference was observed in C. scoticus, $C$. dewulfi or C. chiopterus (Additional file 1: Tables S5-S11).

Solar radiation, wind speed and temperature had a significant impact on catches, with higher trap catches associated with lower solar radiation, lower wind speeds and increased temperatures (Additional file 1: Tables S5, S7, S9 and S11) alongside significant temporal trends in abundance $(P<0.05)$. Light-suction trap collections were

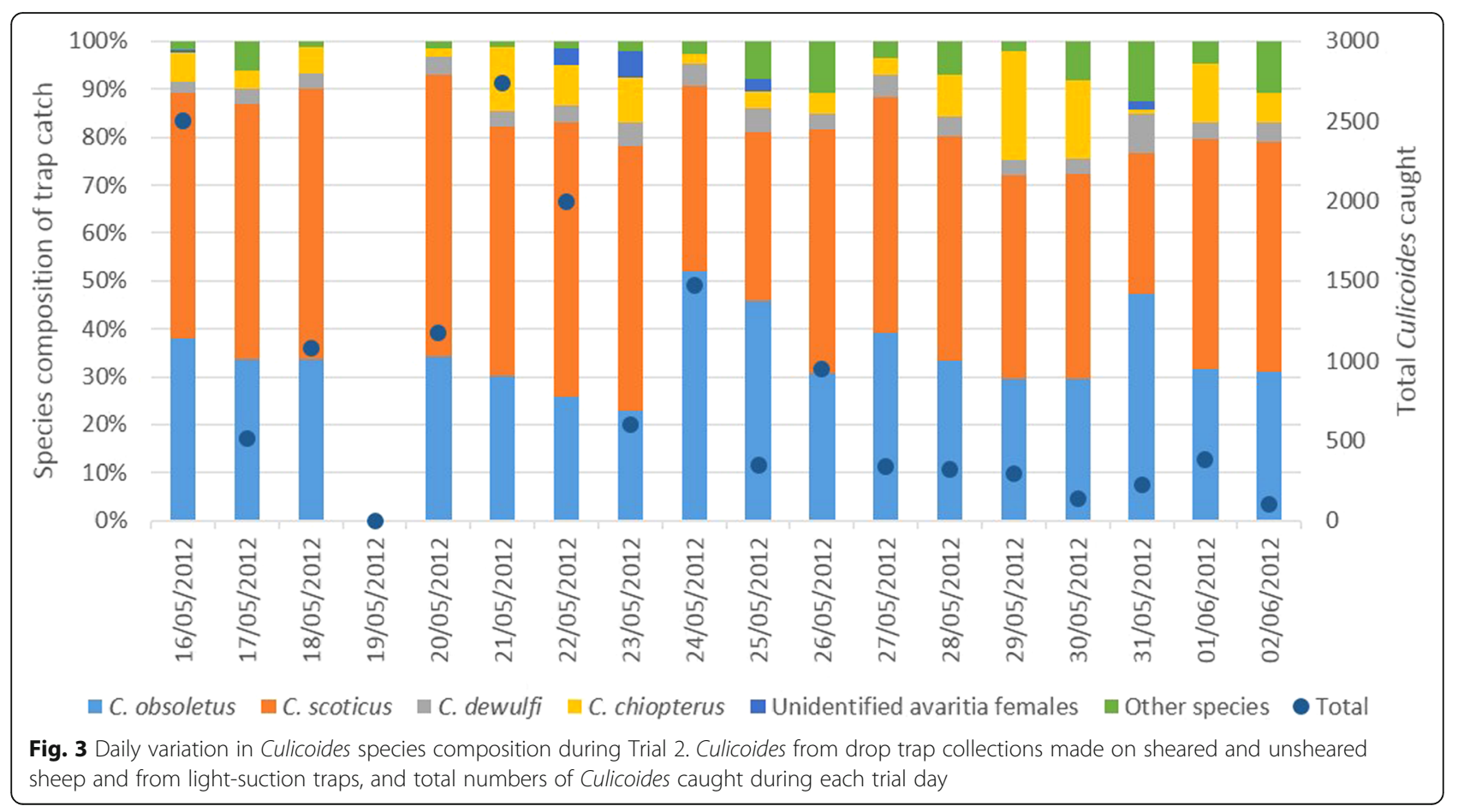


Table 4 Imputed abundance of Culicoides spp. of the subgenus Avaritia and physiological states calculated from sub-samples of total collections from trial two

\begin{tabular}{|c|c|c|c|c|c|}
\hline Species & Physiological status & Sheared & Unsheared & Light trap & Total \\
\hline \multirow[t]{6}{*}{ C. obsoletus } & Unpigmented & 1224 & 1456 & 383 & 3063 \\
\hline & Pigmented & 356 & 501 & 169 & 1026 \\
\hline & Blood-fed & 816 & 173 & 3 & 992 \\
\hline & Gravid & 24 & 7 & 47 & 78 \\
\hline & Male & 24 & 26 & 2 & 52 \\
\hline & Total & 2444 & 2163 & 604 & 5211 \\
\hline \multirow[t]{6}{*}{ C. scoticus } & Unpigmented & 2667 & 2503 & 114 & 5284 \\
\hline & Pigmented & 788 & 597 & 22 & 1407 \\
\hline & Blood-fed & 525 & 482 & 0 & 1007 \\
\hline & Gravid & 0 & 0 & 18 & 18 \\
\hline & Male & 4 & 3 & 0 & 7 \\
\hline & Total & 3984 & 3585 & 154 & 7723 \\
\hline \multirow[t]{6}{*}{ C. dewulfi } & Unpigmented & 146 & 184 & 27 & 357 \\
\hline & Pigmented & 51 & 35 & 15 & 101 \\
\hline & Blood-fed & 18 & 21 & 0 & 39 \\
\hline & Gravid & 7 & 13 & 6 & 26 \\
\hline & Male & 2 & 8 & 0 & 10 \\
\hline & Total & 224 & 261 & 48 & 533 \\
\hline \multirow[t]{6}{*}{ C. chiopterus } & Unpigmented & 14 & 14 & 0 & 28 \\
\hline & Pigmented & 312 & 304 & 0 & 616 \\
\hline & Blood-fed & 226 & 207 & 0 & 433 \\
\hline & Gravid & 1 & 2 & 0 & 3 \\
\hline & Male & 15 & 13 & 0 & 28 \\
\hline & Total & 568 & 540 & 0 & 1108 \\
\hline Total & & 7220 & 6549 & 806 & 14,575 \\
\hline
\end{tabular}

also significantly smaller than collections on sheep across all models and light trap position also influenced catches $(P<0.05)$.

\section{Discussion}

This study clarifies several aspects of Culicoides: host interactions that to date have been only poorly explored and emphasises species specific responses that may influence arbovirus epidemiology. Biting rates recorded were more than five times higher than those found in an experiment previously conducted in the UK [33]. The Culicoides fauna at the site was dominated by the BTV and SBV vectors $C$. obsoletus and C. scoticus, although $C$. chiopterus was also found in significant numbers without being caught in high abundance at light, an underestimation that is thought to result from diurnal activity $[19,43]$. Culicoides pulicaris and C. punctatus, despite being implicated as putative vectors of both SBV $[44,45]$ and BTV [46] were only present in very small numbers on sheep, again in agreement with previous studies in northern
Europe [30, 33]. The response to meteorological conditions were also consistent with previous studies that highlighted peak Culicoides activity under low wind speeds $\left(<3 \mathrm{mps}^{-1}\right)$, warm temperatures $\left(15-25{ }^{\circ} \mathrm{C}\right)$ and low solar intensity $\left(<200 \mathrm{Wm}^{-2}\right)$ [33].

The two sheep breeds selected for the trial were purposefully closely related and of very similar size to reduce the diversity of potential cues used for differentiation. Despite this, breed-specific responses were recorded for both $C$. scoticus and C. dewulfi, which have been implicated in transmission of both BTV $[46,47]$ and SBV [44]. The use of three randomly selected sheep in trials in each replicate was designed to minimise intra-breed variation due to physiological status or physical differences. The biological reasons for the differences found in collections between breeds are unknown. Using silhouettes of cattle and a range of semiochemicals, it has been proposed that visual cues play an important initial role in host location for Culicoides brevitarsis [48]. One possible explanation is that greater numbers of Culicoides were attracted to the 
Hartline/Suffolk crosses due to their black facial pigmentation (Fig. 1). A study on C. sanguisuga in the USA found that collections on darker coloured hosts were higher than those on lighter hosts [49], although these differences were not statistically significant. Paired trials where visual cues could be isolated from other olfactory cues would therefore be informative in isolating factors that might influence attraction [50].

The effect of shearing on the biting and successful feeding rate of Culicoides on sheep had also not been quantitatively investigated prior to this study. Before shearing, the sheep used possessed an extremely thick fleece of 6-8 cm length which covered the majority of the body surface and potentially acted as a barrier to Culicoides bites in certain areas of the body (particularly the belly). It was hypothesised that the presence of the fleece would decrease biting rates due to this mechanical barrier, but that there could also have been a secondary effect on attraction of Culicoides to the host through the emission of greater quantities of semiochemicals from the fleece or as a by-product of increased respiration due to thermal stress.

While it did not apparently impact on host-location, shearing did enable an increase in successful engorgement of C. obsoletus, but not the other three species of the subgenus Avaritia. This could relate to differences in feeding regions as $C$. chiopterus has been found primarily (> 90\%) to feed on the legs of sheep and cattle $[19,51]$ and has also been observed to approach sheep hosts at a very low height (S. Carpenter, personal observation). In contrast $C$. obsoletus and C. obsoletus complex have been found to land on the belly, back and flanks of sheep and cattle while a recent study in Germany showed no significant differences in landing rates on different parts of sheep although the study did not detail species abundance per body part the predominant species in the collections were $C$. obsoletus complex [19, 26, 27, 52]. These studies show that shearing of sheep would be more likely to impact engorgement of $C$. obsoletus complex than it would C. chiopterus. More detailed studies of these differences in behaviour (particularly in C. scoticus and $C$. dewulfi) could explain this apparent differential response to shearing and allow prediction of impact on other species. The effect of host coat on feeding behaviour has been investigated in other species of biting flies showing impact of density and length of coat on biting flies it would be logical, therefore, to assume that length of fleece on sheep would affect the feeding capability of Culicoides species which feed above the legs [52-54]. Ideally, these studies could use the same sheep for pre- and post-shearing assessments, rather than different cohorts in the current study, reducing the impact of individual variation.

As mitigation against infection with arboviruses, the significant reduction in feeding of $C$. obsoletus on the Hartline breed is of interest given its consistent implication as a vector of BTV. Sheep shearing is usually conducted in June-July in the UK, and this timing often coincides with seasonal peaks in Culicoides numbers $[55,56]$. The use of earlier or later shearing, informed by both awareness of local transmission of arboviruses and the presence of reservoir hosts, could therefore impact upon infection. This action, however, would need to be balanced with the cost of delaying or bringing forward shearing and the potential for reduction in efficacy of insecticidal treatments on unsheared sheep [57].

The use of groups of three sheep throughout the trial was necessitated by both ethical and experimental concerns surrounding behaviour of sheep when held individually in the pen. Sheep held individually became distressed with increased respiration and additionally moved around in the pen to a far greater degree. While the use of three sheep in each trial would be expected to reduce the impact of individual variation in attractiveness to Culicoides, this impact cannot be entirely discounted and future studies would be useful in assessing the impact of this phenomenon within this host species.

Previous studies have produced evidence that traditional means of control such as insecticide application to hosts or larval habitat modification can reduce Culicoides host contact rates [7]. There has, however been very limited assessment to date of the impact of such techniques on arbovirus transmission and where trials based on infection have been carried out in the USA and Australia, results have been equivocal $[58,59]$. Both of these studies, however, were carried out using cattle with substantial untreated reservoir populations and intense BTV transmission in close proximity. The impact of integrated approaches to Culicoides control should therefore be a research priority, particularly for scenarios where the probability of transmission is marginal [8].

\section{Conclusions}

The parameters examined in this study are influential in determining the likelihood of transmission of arboviruses. These data will also play a role in future modelling exercises of arbovirus transmission due to a lack of manipulative studies of the genus and additionally provides an insight into the likely utility of shearing in mitigating arbovirus spread.

\section{Additional file}

Additional file 1: Table S1. Regression coefficients for the final negative binomial GLMs for subgenus Avaritia female Culicoides collected on two breeds of sheep. Table S2. Regression coefficients for the final negative binomial GLMs for C. scoticus females collected on two breeds of sheep. Table S3. Regression coefficients for the final negative binomial GLMs for C. dewulfi females collected on two breeds of sheep. Table S4. Regression coefficients for the final negative binomial GLMs for C. chiopterus females collected on two breeds of sheep. Table S5. 
Regression coefficients for the final negative binomial GLMs for collections of C. obsoletus females collected on sheared and unsheared sheep. Table S6. Differences in collections between sheared and unsheared sheep and UV suction-light trap controls for C. obsoletus for total females (a), unpigmented females (b), pigmented females (c) and blood-fed females (d). Table S7. Regression coefficients for the final negative binomial GLMs for collections of C. scoticus females from sheared and unsheared sheep. Table S8. Differences in collections between sheared and unsheared sheep and UV light-suction trap controls for C. scoticus females (a), unpigmented females (b) and pigmented females (c). Table S9. Regression coefficients for the final negative binomial GLMs for collections of $C$. dewulfi females from sheared and unsheared sheep. Table S10. Differences in catch collections between sheared and unsheared sheep and UV light-suction trap controls for C. dewulfi females (a), unpigmented females (b) and pigmented females (c). Table S11. Regression coefficients for the final negative binomial GLMs for collections of $C$. chiopterus females on sheared and unsheared sheep. (DOCX $37 \mathrm{~kb}$ )

\section{Acknowledgements}

The authors acknowledge John Bishop for the provision of animals and a study site for all of the studies in this paper. We also acknowledge Karin Darpel and Eva Veronesi for useful discussions regarding the molecular aspect of the studies. This study has already been published in the public domain by the lead author as part of a PhD thesis: 'Host location and selection by British Culicoides species associated with farms' by A. Hope (University of Liverpool).

\section{Funding}

AH was funded by a BBSRC Doctoral Training Studentship: BBF0164921. FS and SC were funded by the UK National Culicoides Laboratory.

\section{Availability of data and materials}

All data generated or analysed during this study are included within this published article and its additional file.

\section{Authors' contributions}

AH designed experiments, performed studies, carried out analyses, wrote, edited and approved submission. SG advised on statistical analyses, edited and approved submission. CS designed experiments, edited and approved submission. JB performed studies, edited and approved submission. FS performed studies, edited and approved submission. MB designed experiments, edited and approved submission. SC designed experiments, supervised studies, wrote, edited and approved submission. All authors read and approved the final manuscript.

\section{Ethics approval and consent to participate}

No technique used during the trial required ethical approval.

\section{Consent for publication}

Not applicable.

\section{Competing interests}

The authors declare that they have no competing interests.

\section{Publisher's Note}

Springer Nature remains neutral with regard to jurisdictional claims in published maps and institutional affiliations.

\section{Author details}

${ }^{1}$ The Pirbright Institute, Pirbright, Surrey, UK. ${ }^{2}$ Liverpool University Climate and Infectious Diseases of Animals (Lucinda) Group, University of Liverpool, Neston, Cheshire, UK. ${ }^{3}$ Health Protection Research Unit in Emerging and Zoonotic Infections, University of Liverpool, Liverpool, UK.
Received: 4 November 2017 Accepted: 9 July 2018

Published online: 20 August 2018

\section{References}

1. Carpenter S, Mellor PS, Fall AG, Garros C, Venter GJ. African horse sickness virus: history, transmission, and current status. Ann Rev Entomol. 2015:62:343-58.

2. Purse BV, Carpenter S, Venter GJ, Bellis G, Mullens BA. Bionomics of temperate and tropical Culicoides midges: knowledge gaps and consequences for transmission of Culicoides-borne viruses. Ann Rev Entomol. 2015:60:373-92.

3. Rushton J, Lyons N. Economic impact of bluetongue: a review of the effects on production. Vet Italia. 2015;51:401-6.

4. Carpenter S, Wilson A, Mellor PS. Culicoides and the emergence of bluetongue virus in northern Europe. Trends Microbiol. 2009;17:172-8.

5. Roy P, Boyce M, Noad R. Prospects for improved bluetongue vaccines. Nat Rev Microbiol. 2009;7:120-8.

6. Maclachlan NJ, Mayo CE. Potential strategies for control of bluetongue, a globally emerging, Culicoides-transmitted viral disease of ruminant livestock and wildlife. Antiviral Res. 2013:99:79-90.

7. Harrup LE, Miranda MA, Carpenter S. Advances in control techniques for Culicoides and future prospects. Vet Italia. 2016:52:247-64.

8. Mullens BA, McDermott EG, Gerry AC. Progress and knowledge gaps in Culicoides ecology and control. Vet Italia. 2015;51:313-23.

9. Pfannenstiel RS, Mullens BA, Ruder MG, Zurek L, Cohnstaedt LW, Nayduch D Management of North American Culicoides biting midges: current knowledge and research reeds. Vector Borne Zoonotic Dis. 2015;15:374-84.

10. Jeggo MJ, Corteyn AH, Taylor WP, Davidson WL, Gorman BM. Virulence of bluetongue virus for British sheep. Res Vet Sci. 1987;42:24-8.

11. Caporale M, Di Gialleonorado L, Janowicz A, Wilkie G, Shaw A, Savini G, et al. Virus and host factors affecting the clinical outcome of bluetongue virus infection. J Virol. 2014;88:10399-411.

12. Birkett MA, Agelopoulos N, Jensen KMV, Jespersen JB, Pickett JA, Prijs HJ, et al. The role of volatile semiochemicals in mediating host location and selection by nuisance and disease-transmitting cattle flies. Med Vet Entomol. 2004;18:313-22.

13. Jensen KMV, Jespersen JB, Birkett MA, Pickett JA, Thomas G, Wadhams LJ, et al. Variation in the load of the horn fly, Haematobia irritans, in cattle herds is determined by the presence or absence of individual heifers. Med Vet Entomol. 2004;18:275-80

14. Logan JG, Birkett MA. Semiochemicals for biting fly control: their identification and exploitation. Pest Manage Sci. 2007;63:647-57.

15. Kelly DW. Why are some people bitten more than others? Trends Parasitol. 2001;17:578-1.

16. Logan JG, Seal NJ, Cook J, Stanczyk NM, Birkett MA, Clark SJ, et al. Identification of human-derived volatile chemicals that interfere with attraction of the Scottish biting midge and their potential use as repellents. Jed Ent. 2009;46:208-19.

17. Mullens BA, Gerry AC. Comparison of bait cattle and carbon dioxide-baited suction traps for collecting Culicoides variipennis sonorensis (Diptera: Ceratopogonidae) and Culex quinquefasciatus (Diptera: Culicidae). J Med Entomol. 1998;35:245-50.

18. Viennet E, Garros C, Gardes L, Rakotoarivony I, Allene X, Lancelot R, et al. Host preferences of Palaearctic Culicoides biting midges: implications for transmission of orbiviruses. Med Vet Entomol. 2013;27:255-66.

19. Elbers ARW, Meiswinkel R. Culicoides (Diptera: Ceratopogonidae) host preferences and biting rates in the Netherlands: comparing cattle, sheep and the black-light suction trap. Vet Parasitol. 2014;205:330-7.

20. Utech KBW, Wharton RH, Kerr JD. Resistance to Boophilus microplus (Canestrini) in different breeds of cattle. Austral J Agr Res. 1978;29:885-95.

21. Ibelli AMG, Ribeiro ARB, Giglioti R, Regitano LCA, Alencar MM, Chagas ACS, et al. Resistance of cattle of various genetic groups to the tick Rhipicephalus microplus and the relationship with coat traits. Vet Parasitol. 2012;186:425-30.

22. Scasta JD, Koepke K. Host-parasite ecology of keds (Melophagus ovinus (L.)) relative to sheep breed and age on Wyoming rangeland. Livestock Sci. 2016:189:17-22.

23. Lysyk TJ, Steelman CD. Effect of aggregation of horn fly populations within cattle herds and consequences for sampling to obtain unbiased estimates of abundance. J Med Entomol. 2004;41:598-606. 
24. Guglielmone AA, Curto E, Anziani OS, Mangold AJ. Cattle breedvariation in infestation by the horn fly Haematobia irritans. Med Vet Entomol. 2000;14:272-6.

25. Sarre C, Gonzalez-Hernandez A, Van Coppernolle S, Grit R, Grauwet K, Van Meulder $F$, et al. Comparative immune responses against Psoroptes ovis in two cattle breeds with different susceptibility to mange. Vet Res. 2015;46:10.

26. Overgaard Nielsen B. Some observations on biting midges (Diptera: (eratopogonidae) attacking grazing cattle in Denmark. Insect Syst Evol. $1971 ; 2: 94-8$

27. Elbers ARW, Meiswinkel R. Culicoides (Diptera: Ceratopogonidae) and livestock in the Netherlands: comparing host preference and attack rates on a Shetland pony, a dairy cow, and a sheep. J Vector Ecol. 2015;40:308-17.

28. Townley P, Baker KP, Quinn PJ. Preferential landing and engorging sites of Culicoides species landing on a horse in Ireland. Equine Vet J. 1984;16:117-20.

29. Erasmus BJ. Epizootiology of bluetongue - African situation. Austral Vet J. 1975;51:196-8

30. Viennet E, Garros C, Lancelot R, Allene X, Gardes L, Rakotoarivony I, et al. Assessment of vector/host contact: comparison of animal-baited traps and UV-light/suction trap for collecting Culicoides biting midges (Diptera: Ceratopogonidae), vectors of Orbiviruses. Parasit Vectors. 2011;4:119.

31. Broughan JM, Wall R. Fly abundance and climate as determinants of sheep blowfly strike incidence in southwest England. Med Vet Entomol. 2007;21:231-8.

32. Fenton $A$, Wall $R$, French NP. The effect of farm management strategies on the incidence of sheep strike in Britain: a simulation analysis. Vet Parasitol. 1998;79:341-57.

33. Carpenter S, Szmaragd C, Barber J, Labuschagne K, Gubbins S, Mellor P. An assessment of Culicoides surveillance techniques in northern Europe: have we underestimated a potential bluetongue virus vector? J Appl Ecol. 2008;45:1237-45.

34. Hope A. Host location and selection by British Culicoides species associated with farms (2013). https://livrepository.liverpool.ac.uk/16273/. Accessed 10 June 2018.

35. Campbell JA, Pelham-Clinton EC. A taxonomic review of the British species of "Culicoides" Latreille (Diptera, Ceratopogonidae). Proc Roy Soc Edin. 1960; 67:181-302.

36. Mathieu B, Cetre-Sossah C, Garros C, Chavernac D, Balenghien T, Carpenter $\mathrm{S}$, et al. Development and validation of IIKC: an interactive identification key for Culicoides (Diptera: Ceratopogonidae) females from the Western Palaearctic region. Parasit Vectors. 2012;5:11.

37. Dyce AL. The recognition of nulliparous and parous Culicoides (Diptera: Ceratopogonidae) without dissection. J Austral Entomol Soc. 1969;8:11-5.

38. Harrup LE, Purse BV, Golding N, Mellor PS, Carpenter S. Larval development and emergence sites of farm-associated Culicoides in the United Kingdom. Med Vet Entomol. 2013;27:441-9.

39. Garros C, Balenghien T, Carpenter S, Delecolle JC, Meiswinkel R, Pedarrieu A et al. Towards the PCR-based identification of Palaearctic Culicoides biting midges (Diptera: Ceratopogonidae): results from an international ring trial targeting four species of the subgenus Avaritia. Parasit Vectors. 2014;7:9.

40. Nolan DV, Carpenter S, Barber J, Mellor PS, Dallas JF, Mordue AJ, et al. Rapid diagnostic PCR assays for members of the Culicoides obsoletus and Culicoides pulicaris species complexes, implicated vectors of bluetongue virus in Europe. Vet Microbiol. 2007:124:82-94.

41. Schwenkenbecher JM, Mordue AJ, Switek K, Piertney SB. Discrimination of Culicoides midge larvae using multiplex polymerase chain reaction assays based on DNA sequence variation at the mitochondrial cytochrome $c$ oxidase I gene. J Med Entomol. 2009:46:610-4.

42. R Core Team. R: A language and environment for statistical computing. Vienna: R Foundation for Statistical Computing; 2012

43. Meiswinkel R, Elbers ARW. The dying of the light: crepuscular activity in Culicoides and impact on light trap efficacy at temperate latitudes. Med Vet Entomol. 2016;30:53-63.

44. Balenghien T, Pages N, Goffredo M, Carpenter S, Augot D, Jacquier E, et al. The emergence of Schmallenberg virus across Culicoides communities and ecosystems in Europe. Prev Vet Med. 2014;116:360-9.

45. Elbers ARW, Meiswinkel R, van Weezep E, van Oldruitenborgh-Oosterbaan MMS, Kooi EA. Schmallenberg virus in Culicoldes spp. biting midges, the Netherlands, 2011. Emerging Infect Dis. 2013;19:106-9.

46. Hoffmann B, Bauer B, Bauer C, Batza HJ, Beer M, Clausen PH, et al. Monitoring of putative vectors of bluetongue virus serotype 8, Germany. Emerg Infect Dis. 2009;15:1481-4
47. Carpenter S, McArthur C, Selby R, Ward R, Nolan DV, Luntz AJM, et al. Experimental infection studies of UK Culicoides species midges with bluetongue virus serotypes 8 and 9. Vet Rec. 2008;163:589-92.

48. Bishop AL, McKenzie HJ, Spohr LJ. Attraction of Culicoides brevitarsis Kieffer (Diptera: Ceratopogonidae) and Culex annulirostris Skuse (Diptera: Culicidae) to simulated visual and chemical stimuli from cattle. Austral J Entomol. 2008;47:121-7

49. Humphrey JG, Turner EC. Blood-feeding acitivity of female Culicoides (Diptera-Ceratopogonidae). J Med Entomol. 1973;10:79-83.

50. Vale GA. New field methods for studying responses of tsetse flies (Diptera, Glossinidae) to hosts. Bull Entomol Res. 1974:64:199-208.

51. Nielsen BO. Some observations on biting midges (Diptera: Ceratopogonidae) attacking grazing cattle in Denmark. Entomol Scand. 1971;2:94-8

52. Ayllón T, Nijhof AM, Weiher W, Bauer B, Allène X, Clausen P-H. Feeding behaviour of Culicoides spp. (Diptera: Ceratopogonidae) on cattle and sheep in northeast Germany. Parasites \& Vectors. 2014:7:34

53. Mullens BA, Gerhardt RR. Feeding behavior of some Tennessee Tabanidae. Environ Entomol. 1979;8:1047-51.

54. Steelman CD, Brown MA, Gbur EE, Tolley G. The effects of hair density of beef cattle on Haematobia irritans horn fly populations. Med Vet Entomol. 1997;11:257-64.

55. Searle KR, Barber J, Stubbins F, Labuschagne K, Carpenter S, Butler A, et al Environmental drivers of Culicoides phenology: how important is speciesspecific variation when determining disease policy? PloS One. 2014;9:11.

56. Sanders CI, Shortall CR, Gubbins S, Burgin L, Gloster J, Harrington R, et al. Influence of season and meteorological parameters on flight activity of Culicoides biting midges. J Appl Ecol. 2011;48:1355-64.

57. Venail R, Mathieu B, Setier-Rio ML, Borba C, Alexandre M, Viudes G, et al Laboratory and field-based tests of deltamethrin insecticides against adult Culicoides biting midges. J Med Entomol. 2011;48:351-7.

58. Mullens BA, Gerry AC, Velten RK. Failure of a permethrin treatment regime to protect cattle against bluetongue virus. J Med Entomol. 2001;38:760-2.

59. Melville LF, Hunt NT, Bellis G, Pinch D. An assessment of insecticides to minimize the transmission of arboviruses in cattle. Arbo Res Austral. 2004:8:249-55.
Ready to submit your research? Choose BMC and benefit from:

- fast, convenient online submission

- thorough peer review by experienced researchers in your field

- rapid publication on acceptance

- support for research data, including large and complex data types

- gold Open Access which fosters wider collaboration and increased citations

- maximum visibility for your research: over $100 \mathrm{M}$ website views per year

At $\mathrm{BMC}$, research is always in progress.

Learn more biomedcentral.com/submissions 